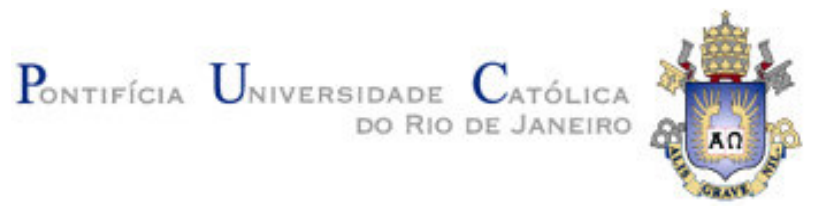

Tomás Mendonça da Silva Prado

\title{
As esquinas da linguagem e da técnica Em Martin Heidegger
}

Dissertação de Mestrado

Dissertação apresentada ao programa de Pósgraduação em Filosofia da PUC-Rio como requisito parcial para obtenção do título de mestre em Filosofia.

Orientador: Prof. Dr. Eduardo Jardim de Moraes

Rio de Janeiro Março de 2008 


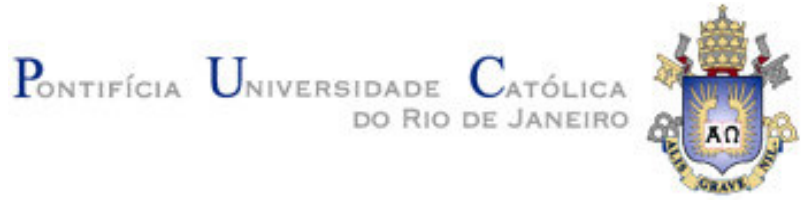

Tomás Mendonça da Silva Prado

As esquinas da linguagem e da técnica
Em Martin Heidegger

Dissertação de Mestrado

Dissertação apresentada ao programa de Pósgraduação em Filosofia da PUC-Rio como requisito parcial para obtenção do título de mestre em Filosofia. Aprovada pela comissão examinadora abaixo assinada.

Prof. Dr. Eduardo Jardim de Moraes

Orientador

Departamento de Filosofia - PUC-Rio

Prof. Dr. Edgar de Brito Lyra Netto

Departamento de Filosofia - PUC-Rio

Prof. Dr. Patrick Estellita Cavalcanti Pessoa

UFRJ

Prof. Paulo Fernando Carneiro de Andrade Coordenador Setorial do Centro de Teologia e Ciências Humanas - PUC-Rio 
Todos os direitos reservados. É proibida a reprodução total ou parcial do trabalho sem autorização da universidade, do autor e do orientador.

Tomás Mendonça da Silva Prado

Graduou-se, no ano de 2005, na faculdade de Filosofia da Universidade Federal do Rio de Janeiro. Presta serviços ao PróSaber (Instituto Superior de Educação, instituição de utilidade pública).

Ficha Catalográfica

Prado, Tomás Mendonça da Silva

As esquinas da linguagem e da técnica em Martin Heidegger / Tomás Mendonça da Silva Prado ; orientador: Eduardo Jardim de Moraes. - 2008.

132 f. ; $30 \mathrm{~cm}$

Dissertação (Mestrado em Filosofia)-Pontifícia Universidade Católica do Rio de Janeiro, Rio de Janeiro, 2007.

Inclui bibliografia

1. Filosofia - Teses. 2. Linguagem. 3. Técnica. 4. Poesia. I. Moraes, Eduardo Jardim de. II. Pontifícia Universidade Católica do Rio de Janeiro. Departamento de Filosofia. IV. Título.

CDD: 100 
Para toda a minha família.

Para Lua e Lara, pelo afeto.

Para Gustavo, pelo diálogo.

Para Wilma, pela alegria.

Para Margarida e Ricardo, pela presença.

Para Beatriz, por estar ao meu lado e me fazer feliz. 


\section{Agradecimentos}

Ao Conselho Nacional de Pesquisa (CNPq).

Aos profissionais do Departamento de Filosofia da PUC-Rio.

Ao meu orientador, Prof. Dr. Eduardo Jardim de Moraes, pela confiança e pelas contribuições fundamentais para o desenvolvimento da proposta e do percurso deste trabalho.

Aos professores Edgar Lyra, Emmanuel Carneiro Leão, Fernando Rodrigues, Paulo César Duque Estrada e, especialmente, Gilvan Fogel, pelos cursos sobre o pensamento de Martin Heidegger.

Ao primeiro professor de Filosofia, Patrick Pessoa, pela amizade, pelo incentivo e pelas contribuições em minha formação.

À Maria Seabra Loubet e ao Georges Loubet, pelos livros e pelas conversas que contribuíram para essa pesquisa.

Aos amigos Pedro Bastos e Tomás da Costa, pela boa filosofia de botequim.

À Hilana Erlich, pela escuta.

Ao Pró-Saber, e especialmente à Madalena Freire e à Maria Cecília Almeida e Silva, pelo valioso aprendizado profissional e pela privilegiada experiência humana. 


\section{Resumo}

Prado, Tomás Mendonça da Silva; Moraes, Eduardo Jardim de. As esquinas da linguagem e da técnica em Martin Heidegger. Rio de Janeiro, 2008. 132p. Dissertação de Mestrado - Departamento de Filosofia, Pontifícia Universidade Católica do Rio de Janeiro.

Acompanhando o pensamento de Martin Heidegger, apresentaremos os riscos e deficiências das compreensões ordinárias da linguagem e da técnica e ofereceremos, como alternativa, um percurso de reencontro da origem desses problemas, onde vigora o essencial. A origem de ambas se encontra obstruída por uma experiência dominante - a técnica moderna -, que as submete aos seus anseios de controle e utilidade. Compreendendo o que é a técnica moderna, poderemos desobstruir o caminho para a essência da técnica e da linguagem. É preciso ver o que é técnica para rever o que é produção. Onde linguagem e técnica compactuam, o homem não se perde em ocupações alienadas e arbitrárias, mas é livre para a produção de sentidos comprometida com o que é necessário.

\section{Palavras-chave}

Linguagem; Técnica; Poesia 


\section{Abstract}

Prado, Tomás Mendonça da Silva; Moraes, Eduardo Jardim de (Advisor). The corners of language and technique in Martin Heidegger. Rio de Janeiro, 2008. 132 p. MSc. Dissertation - Departamento de Filosofia, Pontifícia Universidade Católica do Rio de Janeiro.

Following the thoughts of Martin Heidegger, we intend to expose the risks and deficiencies of the ordinary understandings of language and technique as well as to offer, as an alternative, a path to the origin of these problems, where the essential dwells. The origin of both is, at any point in time, already obstructed by a dominating experience - the modern technique. The modern technique submits language to it's control and utility yearnings. By comprehending what modern technique is, we will be able to clear the path to the essence of technique and language. We must understand what technique is in order to revise what production is. Where language and technique meet, men do not get lost in alienated and arbitrary occupations, but are free for a senses production committed with what is necessary.

\section{Keywords}

Language; Technique; Poetry 


\section{Sumário}

1. Introdução Logos: o caminho que reúne 10

2. A vigência da técnica

2.1 Pensamento meditativo e pensamento calculativo 28

2.2 A compreensão habitual sobre a técnica 34

2.3 A essência da técnica vigente (moderna) 40

2.4 Fausto, o domínio sobre a terra e a vingança de Mefistófeles 44

3. A linguagem submetida à técnica moderna

3.1 Nimrod e a torre de Babel; Gilgamesh e a imortalidade $\quad 54$

$\begin{array}{ll}\text { 3.2 Linguagem e o caminho da Metafísica } & 62\end{array}$

$\begin{array}{ll}3.3 \text { Signo: significante e significado } & 70\end{array}$

3.4 A linguagem submetida à técnica moderna 80

4. A linguagem em acordo com a essência da técnica

4.1 A favor da experiência $\quad 88$

4.2 A essência da linguagem $\quad 94$

4.3 A essência da técnica $\quad 110$

$\begin{array}{ll}\text { 4.4 Linguagem e poesia } & 117\end{array}$

$\begin{array}{ll}\text { 5. Conclusão } & 123\end{array}$

6. Bibliografia 126

7. Apêndice. Apropriação: limite, serenidade e memória 129 
Como abranger-te, ó natureza infinda?

W. Goethe

De resto, esse século se me afigura como o tonel eternamente vazio das Danaides, e minha alma jorrou esbanjando amor para preencher todas as lacunas. Então não vi mais nenhuma lacuna, e o tédio da vida não mais me oprimiu. Nunca mais disse então à flor, "você é minha irmã!", e às fontes, "somos da mesma espécie!". Fielmente, como um eco, dei a cada coisa o seu nome. (...) A linguagem é um grande excesso. O melhor, porém, sempre permanece para si e descansa em suas profundezas como a pérola no fundo do mar...

\section{F. Hölderlin}

